\title{
Value chains for sustainable procurement in large school districts: Fostering partnerships
}

\author{
David S. Conner, ${ }^{*}$ Andrew Nowak, ${ }^{\mathrm{a}}$ JoAnne Berkenkamp, ${ }^{\mathrm{b}}$ Gail W. Feenstra, ${ }^{\mathrm{c}}$ Julia Van Soelen Kim, ${ }^{\mathrm{d}}$ \\ Toni Liquori, ${ }^{e}$ and Michael W. Hamm ${ }^{\mathrm{f}}$
}

Submitted 15 February 2011 / Accepted 11 May 2011 / Published online 30 June 2011

Citation: Conner, D. S., Nowak, A., Berkenkamp, J., Feenstra, G. W., Van Soelen Kim, J., Liquori, T., \& Hamm, M. W. (2011). Value chains for sustainable procurement in large school districts: Fostering partnerships. Journal of Agriculture, Food Systems, and Community Development, 14), 55-68. http://dx.doi.org/10.5304/jafscd.2011.014.005

Copyright (C) 2011 by New Leaf Associates, Inc.

\begin{abstract}
Values-based value chains and farm to school programs are two aspects of the alternative agrifood system that have received a great deal of
\end{abstract}

\footnotetext{
* Corresponding author: David Conner, Assistant Professor, Department of Community Development and Applied Economics, 205H Morrill Hall, University of Vermont, Burlington VT 05405 USA; +1-802-656-1965; david.conner@uvm.edu

a Project Director, Seed To Table School Food Program, Slow Food Denver, Denver, CO USA; District Partner for Denver Public Schools.

b Program Director for Local Foods, Institute for Agriculture and Trade Policy, Minneapolis, MN USA;

District Partner for Saint Paul Public Schools.

c Food Systems Analyst, Agricultural Sustainability Institute, University of California, Davis, CA USA.

d Graduate Student Researcher, Agricultural Sustainability Institute, University of California, Davis, CA USA.

e Adjunct Full Professor, Nutrition Program, Teachers College Columbia University, New York City, NY USA.

${ }^{\mathrm{f}}$ C.S. Mott Professor of Sustainable Agriculture; Depts. of Community, Agriculture, Recreation and Resource Studies, Food Science and Human Nutrition, Crop and Soil Sciences; Michigan State University, East Lansing, MI USA.
}

attention recently from scholars and practitioners. This paper chronicles two separate pilot efforts to create value chains for mid-scale farms to supply large school districts' food-service operations with more healthful, local, and sustainably produced foods, using a modified farm to school model. Early farm to school efforts were mostly farmdirect, a model that poses difficulty for large districts, which often require some kind of intermediary to procure the volume and form of products required for the scale of their foodservice operations. Value chains have the potential to address this issue, as part of a more broad-based sustainable school food procurement model that can met the needs of large districts. The lessons learned about the various roles scholars and

\section{Disclosures}

David Conner is a consultant to School Food FOCUS.

Gail Feenstra and Julia Van Soelen Kim are evaluators for School Food FOCUS.

Toni Liquori is executive director and co-principal investigator for School Food FOCUS.

Michael Hamm is co-principal investigator for School Food FOCUS. 
community partners might play in creating, sustaining, and monitoring performance of these value chains are highlighted.

\section{Keywords}

farm to school, large school districts, participatory research, partnerships, practitioners, school meals, urban school districts, values-based value chains

\section{Introduction}

Partnerships among diverse stakeholders are effective means of identifying and acting upon opportunities for food system-based community economic development (Conner, Cocciarelli, Mutch, \& Hamm, 2008; Conner, Knudson, Hamm, \& Peterson, 2008; Wright, Score, \& Conner, 2008). This paper chronicles efforts to create values-based value chains (VCs) for mid-scale farms to supply large school districts' food-service operations using a sustainable school food procurement model. First, we discuss previous research on institutional food procurement, particularly farm to school (FTS), and VCs, which suggests that VCs may be well suited to address many of the well known barriers of FTS. Then we present two cases that illustrate the efforts of two large school districts ${ }^{1}$ - one in Saint Paul, Minnesota, and one in Denver, Colorado - to procure more healthful, local, and sustainably grown foods. The two cases provide a look at on-the-ground VC developments, as well as the key lessons learned about the various roles scholars and community partners might play in creating, sustaining, and monitoring performance of these VCs. Finally we conclude with a statement of how our research might inform partnerships among other school food-service professionals, scholars, and community partners to create VCs that bring broad benefits to schoolchildren, farmers, local economies, and communities.

\footnotetext{
1 The typical designation of a "large" school district is one that enrolls at least 40,000 students. According to this criterion, there are 137 large school districts in the United States (Common Core Data (CCD) public school district data (20082009), U.S. Department of Education's National Center for Education Statistics (NCES), at http://nces.ed.gov/ccd/)
}

\section{Background}

Institutional food procurement, particularly farm to school (FTS), has received a great deal of attention recently from agri-food scholars and practitioners. The strategy has been cited as among the most important aspects of alternative agri-food movement (Izumi, Wright, \& Hamm, 2009; Kloppenburg, Wubben, \& Grunes, 2008), although some scholars believe it does not sufficiently challenge fundamental injustices in the present day food system (Allen \& Guthman, 2006). FTS typically combines the procurement of locally grown foods with experiential education to instill good nutrition habits in students and to enhance the viability of small and mid-scale farms (Allen \& Guthman). The experiential education component often teaches students how, where, and by whom food is grown, fostering closer relationships between consumers and farmers. For example, one recent study suggests the potential when food comes from farmers known to students: this food is seen as "cool," resulting in increased student consumption of healthful foods (Izumi, Alaimo, \& Hamm, 2010).

FTS's potential to sustain demand for alternative agri-food products is significant, both because of the magnitude of expenditures in the National School Lunch Program (US $\$ 9.8$ billion annually and 31 million meals daily in 2009) and its purported ability to create lasting demand for healthful sustainably and locally grown foods (USDA Food and Nutrition Service, 2009; Vallianatos, Gottlieb, $\&$ Hasse, 2004). FTS also is receiving national attention as it plays a central role in the United States Department of Agriculture (USDA)'s "Know Your Farmer, Know Your Food" and first lady Michelle Obama's "Let's Move" campaign to combat childhood obesity and promote wellness (Bottemiller, 2010; USDA, 2010).

To date, most FTS efforts have consisted of the farm-direct model, in which local farmers deliver food directly to schools for use in their school meal programs. This FTS model poses many potential obstacles to large school districts due to the large quantities demanded by the scale of their operations (Berkenkamp, 2006). A national collaborative, 
School Food FOCUS, ${ }^{2}$ has recently emerged to leverage the knowledge and procurement power of large school districts to make school meals more healthful, regionally sourced, and sustainably produced. School Food FOCUS aims to address food procurement practices at the intersection between large school districts and their supply chains, which ultimately include mid-scale farms and ranches. While resolving procurement challenges related to scale in large school districts is a complex and longterm process requiring political and institutional change, School Food FOCUS aims to catalyze change from within school food-service operations, especially in regard to sustainable food procurement. In general, school food procurement practices include activities such as bidding and specifications, as well as attention to regulations that affect food purchases. While a robust and detailed national discussion on sustainable procurement practices in school food is needed, for the purposes of this paper, food procurement practices are considered sustainable if their use leads to the acquisition of safe, affordable, and nutritious products in ways that (1) prioritize whole and minimally processed foods; (2) promote more locally and regionally focused food production, processing and distribution systems; and (3) enhance and sustain the economic, environmental, and social systems of the communities in which these food systems are embedded (One Tray Coalition, 2009).

In addition to farm to school research, agri-food scholars and practitioners have focused their attention on the loss of mid-scale farms in the United States. Mid-sized farms, it is argued, lack

\footnotetext{
2 School Food FOCUS (Food Options for Children in Urban Schools) is a national collaborative of large school districts, community partners, university-based scholars, and nonprofit organizations. FOCUS leverages the knowledge and procurement power of large school districts to make school meals nationwide more healthful, regionally sourced, and sustainably produced. Funded by the W.K. Kellogg Foundation and launched in late 2008, FOCUS aims to transform food systems to support students' academic achievement and lifelong health, while directly benefiting farmers, regional economies, and the environment. For more information, see http://www.schoolfoodfocus.org.
}

sufficient volume to survive on the slim margins of commodity markets; yet they also are not well suited to sell differentiated products in direct-toconsumer markets (Pirog, 2004; Stevenson \& Pirog, 2008). One study outlined the nearly ubiquitous loss of mid-scale farms and the associated loss of consumer choice, rural economic prosperity, environmental stewardship, and social capital (Kirschenmann, Stevenson, Buttel, Lyson, \& Duffy, 2008). Nevertheless, mid-sized farms play an important role in regional economies, and the importance of mid-scale family farms to overall community well-being has been well documented (Goldschmidt, 1947; Lyson, Torres, \& Welsh, 2001; Welsh \& Lyson, 1997).

One promising market mechanism to create appropriate markets for mid-scale farming is the VC. VCs differ from traditional supply chains in several keys ways (Bloom \& Hinrichs, 2011; Stevenson \& Pirog, 2008), including adding value to products through differentiation, and creating strategic partnerships that contribute to the welfare of all participants. VCs potentially can meet growing demand for differentiated products with attributes such as how, where, and by whom the food was produced, or the "story" of the food (Conner, Campbell-Arvai, \& Hamm, 2008a; Kirschenmann et al., 2008). VCs are well suited to deliver a high volume of product to regional markets through strategic partnerships, creating viable outlets for mid-scale farms and creating value for customers and other supply chain actors (Stevenson \& Pirog, 2008). To date, many VCs discussed in the literature (e.g., Stevenson, 2009) can be characterized as a supply-push approach, as they are initiated by farmers and ranchers with the intent of benefitting the producers by creating markets for differentiated products. In contrast, this study examines the potential of VCs from a demand-pull approach, as they were initiated by school food-service operations to procure food with desired attributes.

Recent research (Berkenkamp, 2006; Izumi et al., 2009; Lawless, Stevenson, Hendrickson, \& Cropp, 1999; Strohbehn \& Gregoire, 2008; Vogt \& Kaiser, 2008) suggests a set of barriers commonly found in FTS efforts, including: 
- lack of reliable supply of consistently high quality product;

- logistical difficulties and high transaction costs;

- reliance on processed rather than whole and/or raw products (for example, pre-cut produce and pre-cooked meats); and

- difficulties in creating seasonal menus using regional products.

In addition, FTS efforts have typically focused on farm-direct purchases with a limited variety of fresh fruits and vegetables, and they have rarely touched the "center of the plate" protein-based entrée (Bagdonis, Hinrichs, \& Schafft, 2009; Berkenkamp, 2006). Some studies argue that school markets are predominantly supplied by large farms and only make up a small percentage of sales for smaller and mid-sized farms (Allen \& Guthman, 2006; Izumi, Wright, \& Hamm, 2010). VCs have the potential to increase procurement from and create greater income for small and midsized producers.

Additionally, FTS can pose barriers for school districts with highly routinized, mechanized preparation systems or underequipped kitchen infrastructure (Berkenkamp, 2006; Kloppenburg et al., 2008). Many schools therefore choose to work through broadline distributors, offering reliable, one-stop shopping for a wide variety of products in easy-to-use form (Izumi, Wright, \& Hamm, 2009). The information about how, by whom, and where food is produced is typically lost in these long and obscure supply chains, yet relationships with the farmers are instrumental to the experiential education component featured in many FTS programs. FTS program practitioners and evaluators conclude that one of the keys to success for FTS is complementary partnerships in which supply chain and community stakeholders communicate with each other and work together for common solutions (Joshi, Azuma, \& Feenstra, 2008).

In theory, VCs can address many of the aforementioned barriers of FTS by supplying high quality food, in the proper form and quantity for use by school food service, along with the "story" intact for education and marketing efforts. VCs can operate on a regional level to better manage seasonal and local shortages while maintaining high production and quality standards. Strategic partnerships with processors and distributors can help manage transaction costs and aid with logistics and processing farm commodities into the needed form for use in school food. Price is, however, a lingering barrier; most currently existing VCs sell to relatively high-end retailers or restaurants that do not have the strict price constraints that schools' food-service programs operate within (Stevenson, 2009). Strategies for making VCs' products affordable to schools will be an important task and critical test of their compatibility with FTS efforts and goals.

The remainder of this paper discusses efforts to apply the concept of VCs to supply chain development to help meet school food-service procurement goals toward sourcing more healthful, sustainable, and locally produced foods. This analysis is highly exploratory in nature. We begin by introducing the two cases, and then discuss outcomes and future prospects with particular emphasis on lessons learned, institutional changes, and implications for replication.

\section{Fostering Partnerships in Practice: Approach, Actions, and Outcomes}

The cases. This section reports on efforts in two large school district meal programs, Saint Paul Public Schools (SPPS) in Minnesota and Denver Public Schools (DPS) in Colorado, to procure and serve more healthful, sustainable, and locally grown foods. These two cases are used because they were the first pilot districts in the School Food Learning Lab, a program of School Food FOCUS ${ }^{3}$ in which

\footnotetext{
${ }^{3}$ The Learning Lab engages selected school districts in a collaborative research process conducted over an 18-month period to discover methods for transforming food options within their operations. Each lab brings school food-service professionals and district partners together with research and technical assistance to study and work on specific procurement goals. The labs also create valuable learning experiences and
} 
the authors are all involved in some way. Both districts identified several food priorities they wished to address through the Learning Lab; we will concentrate on two of the priorities' supply chains that best demonstrate VC principles: fresh, local produce at SPPS and pasture-raised, local beef at DPS. Greater detail of other priority items, supply chain actors, background on the schools, and the overall methodological approach of the School Food FOCUS project are available elsewhere (Abate, Conner, Brayley, \& Modzelewski, 2009a, 2009b; Conner, Abate, Liquori, Hamm, \& Peterson, 2010; Feenstra, Ohmart, \& Van Soelen, 2009).

Methods. For each school district, the Learning Lab team began by holding discussions with the school team to better understand its current and desired procurement practices. Then, the Learning Lab and school teams collaboratively developed a series of research questions to help guide sound procurement decisions and lead to desired changes. The school team also assisted in purposive identification and sampling of interviewees among current and prospective product vendors and stakeholders in local, state, and federal government. During the course of the project, members of the Learning Lab visited each research site three times and conducted a total of 43 interviews: 17 interviews in Minnesota (in December 2008, February 2009, and November 2009) and 26 in Colorado (in June 2009, October 2009, and April 2010). Interviews were held with government officials, members of industry groups, and with current and potential vendors. This paper focuses on the results of interviews of the two aforementioned VCs: fresh local produce (two distributors and two farmers) at SPPS and pasture-raised local beef at DPS (one rancher-meat processor and one quick-chill processor). At each interview, Learning Lab members took extensive notes, which were compiled into a single document and shared with the school districts for validation. In addition to the shared notes, initial impressions and observations were shared at debriefing meetings at the end

transmit emerging practices to the school districts participating in School Food FOCUS. of each visit. We also discussed opportunities for procurement changes, planned action steps, and monitored progress. The notes from the interviews were then analyzed by the lead author of this paper, identifying supply chain actors' attitudes and behaviors, particularly in terms of the presence or absence of $\mathrm{VC}$ principles and behaviors and their role in addressing sustainable school food procurement needs in large school districts.

In addition, the lead author interviewed a district partner ${ }^{4}$ at each location to gain his or her insights on the Learning Lab processes and outcomes. Questions were vetted with the evaluation team and focused on needs and assets of each supply chain partner; lessons learned and knowledge gained about forming and sustaining the value chains; institutional changes; benefits of participation; next steps; lingering barriers; keys to success, and lessons for practitioners. Evaluation team members had also conducted four to five interviews with school district personnel and school district partners, in each case focusing on the VC processes, opportunities, and barriers to success. Interviews were transcribed, summarized into reports, and shared with the author for this paper. Finally, a draft of this paper was sent to members of each school district team for final verification of results.

From the beginning of the project, the Learning Lab utilized participatory action research approaches and principles: broad participation; equitable partnerships; recognition of multiple determinants of problems; co-learning; cyclical, iterative processes; local capacity-building; utilization of community strengths and assets; empowerment; and problem solving (Pavlovich, 2004). We also used steps common to participatory research, including collective analysis and determination of issues to be addressed, followed by research, sharing critical understanding with

\footnotetext{
${ }^{4}$ The district partner for Saint Paul Public Schools is the program director for local foods at the Institute for Agriculture and Trade Policy, Minneapolis, MN. The district partner for Denver Public Schools is the project director at the Seed To Table School Food Program, Slow Food Denver (CO).
} 
partners, and creating action steps to address the problem (Minkler, 2000; Pavlovich, 2004). Our intent was to "put the school food professionals in the driver's seat," in the words of the SPPS director of nutrition services and commercial services.

Given the complexity of the operations and regulations within the businesses in our study - school food operations and their supply chains actors we also adopted an orientation of co-learning, sharing, and discussing findings among school district partners, school food-service professionals, and supply chain actors within the Learning Labs and the wider project. This orientation helped us to develop action steps that fit within the business practices of the VC partners. In addition, district partners were critical in these efforts. The school districts selected these individuals or organizations because they brought a unique perspective to the team, provided logistical and content-area support, and provided expert knowledge on a host of local relationships that advanced the school district work, particularly knowledge of the local food system.

\section{Results}

The SPPS Case: Starting Point, Actions, and Outcomes

School meals at SPPS are served by Nutrition and Commercial Services, a self-operated division of the school district. SPPS has an enrollment of about 38,000 students, $70 \%$ of whom are eligible for free and reduced-price meals. In 2009-2010, they served, on average, about 16,000 breakfasts and 29,000 lunches per day. Food preparation is done in a central commissary and meals are delivered to each of 56 locations. Prior to their engagement with School Food FOCUS, their local procurement efforts were limited largely to local apples from a Minnesota-based aggregator. SPPS chose to be part of the Learning Lab because they felt they needed to increase their momentum toward sustainability goals and get away from "feeling stuck" on issues and they were eager for fresh eyes and a different perspective on their current systems (Feenstra et al., 2009).
Additionally, they realized they needed to be able to allot more time, resources, and focused attention to make substantial change, and they thought the FOCUS initiative would help make that happen (Feenstra et al.).

SPPS wanted to serve more locally grown fresh produce in their school meals, as a means of enhancing their nutrition education goals as well as benefitting local farmers by providing more transparency in the process and to ensure the farmers got a fair price for the produce. When the Learning Lab began, SPPS was sourcing 34 pre-cut produce items, from two Twin Cities-based processordistributors, and they were generally happy with the quality of product, logistics, and price. The Learning Lab interviewed sales agents from the two vendors, as well as mid-scale farmers and representatives of a statewide fruit and vegetable growers' organization. The processor-distributors reported willingness to source more locally grown produce, especially if they had adequate time to contact local growers. The growers were primarily interested in creating reliable markets for their products and receiving a fair price.

The team worked together to develop a request for proposals (RFP) for local produce, which invited bids for 14 pre-cut local produce items grown within 200 miles of the Twin Cities. The RFP also requested information on the farms' names and locations and the final prices paid to farmers. Before finalizing the RFP, the district partner convened a meeting of the school food-service professionals, the two processor-distributors, and a group of farmers to vet the document. The purpose was to clarify the goals for the schools in sourcing local produce and to understand the constraints for other members of the VC. This enabled produce distributors to know that they were in competition with one another and provided the farmers a chance to share their perspectives and to see how different types of supply chain relationships would affect them. As a result, the RFP was vetted by the school district, vendors, and farmers, and then was revised to meet the needs of all parties. 
Both processor-distributors submitted bids for the RFP and one received the contract. During the four months that the RFP was active (September through December 2009), SPPS purchased 173,000 pounds $(78,471 \mathrm{~kg})$ of local produce at a cost of about US $\$ 130,000$. This represents about $40 \%$ of total produce purchases during this time period and includes 14 items sourced from six farmers within a 100-mile radius. Subsequent interviews with two of the farms supplying the vendor found general satisfaction with the pricing and other arrangements. No locally grown fresh vegetables for the 2009-2010 school year were sourced after this date, however, reflecting the challenge of seasonality. The processor-distributor who did not win the contract continued to supply many other nonlocally grown fresh produce items to SPPS throughout the year.

The RFP process was expanded for the 2010-2011 school year. SPPS purchased about 225,000 pounds $(102,058 \mathrm{~kg})$ of local produce, spending about US $\$ 130,000$. This represents a smaller percentage of the overall fresh produce purchased by SPPS due to a significant expansion of school breakfast programs and concomitant increase in nonlocal fruits like bananas, kiwi, mangos, oranges, and pineapple. The processor-distributor who won the 2009-2010 contract supplied all local items under the RFP except for potatoes, which were supplied by other processor-distributors.

\section{The DPS Case: Starting Point, Actions, and Outcomes}

School meals at DPS are served through DPS's Nutrition Services, a self-operated division of the school district. DPS has an enrollment of about $73,000,66 \%$ of whom are eligible for free and reduced price meals. DPS serves about 14,000 breakfasts and 39,000 lunches per day. Food is prepared at various kitchens throughout the district and delivered to 156 schools. Prior to working with the Learning Lab, DPS was mainly sourcing locally grown produce for Colorado Proud Day and was interested in increasing procurement of locally grown foods across all food groups.
As part of their involvement with FOCUS, DPS wanted to source locally produced beef in their school meals. In October 2009, the Learning Lab met with a rancher who also operated a meat processing plant with a retail outlet. This person (heretofore called the "meat processor") operates the processing plant in part to give smaller-scale farmers and ranchers the opportunity to get their meat to market. The meat processor was able to sell steaks and roasts at good prices, but was left with a surplus of ground beef. He was selling ground beef to another Colorado school district on a very limited basis. DPS was interested in this beef but had just started to train personnel to handle raw meat, so they were concerned about the consistency of finished product and believed a quick-chill processor could help address this. This processor was willing to work with DPS in a capacity similar to the one they envisioned. As a result, from September 2010 to May 2011, DPS bought 137,010 pounds $(62,147 \mathrm{~kg})$ of local beef from the meat processor at a cost of about US $\$ 349,000$. This beef was served in three forms: 6,480 pounds $(2,939 \mathrm{~kg})$ processed by the quickchill processor into crumbles for beef stew, chili, and Sloppy Joes; 84,000 pounds $(38,102 \mathrm{~kg}$ ) of raw ground beef used in items such as in tacos and various pasta dishes; and 46,530 pounds (21,106 $\mathrm{kg}$ ) formed into patties for hamburgers and cheeseburgers. Dishes using this local ground beef were served about once a week at all schools. Local patties were served daily at high schools and about once a month in middle and elementary schools.

\section{Assets and Needs of Each VC Partner}

In both cases, each of the VC partners had both unique assets and needs that had to be addressed in order for the VC to function. In the case of SPPS, the Minnesota farmers could provide fresh, seasonal produce along with the educational and marketing value of their farms' names and stories attached to the food; in return, farmers needed a reliable market for their products at a fair price. The Twin Cities-based processor-distributors had aggregating, storage, processing, delivery, and invoicing capacity, which addresses many of the barriers and limitations of farm- direct deliveries to schools; in return, they needed to understand how 
to fill their clients' demand, including what local produce items, in what form, on what dates, and how much of the food's story to communicate. SPPS provided reliable demand for relatively large quantities of produce and a desire to support its own nutritional goals and local farms with their purchases. They also brought a desire to provide more transparency in the process, to develop relationships with the farmers, and to ensure the farmers got a fair price for the produce. However, they lacked the time and capacity to step away from routine procurement in order to investigate and implement options to meet their goals.

In the case of DPS, the Colorado meat processor had a surplus of ground beef needing an appropriate market and a desire to help educate schoolchildren about the value of locally grown healthy foods. The quick-chill processor had the capacity to receive, cook, chill, and deliver the product, as well as the expertise to work with DPS's recipes and nutritional standards. DPS provided relatively large demand for the product but needed outside assistance to bring consistency to the preparation of the product while the kitchen staff was being trained to handle raw meat safely.

\section{Lessons Learned About Forming and Sustaining the Value Chains}

In each of the cases, VC actors learned lessons and gained knowledge that helped them form the VCs and (hopefully) to sustain them over time. Specifically, the Minnesota farmers learned about the school food market, particularly that it can be a viable market for \#2 grade products (appropriate for pre-cut produce, but not cosmetically perfect enough for retail) and an outlet for unexpected surplus items. The distributors learned that the school was serious about local produce and about the district's desire for transparency and fairness for all partners. SPPS learned about the capacities of their two distributors to source locally: one responded to and fulfilled the RFP with relative ease; the other submitted much higher bids and lacked needed connections with local farmers.

In Colorado, the meat and quick-chill processors and DPS learned of each other's existence and their mutual determination to serve high quality food. The quick-chill processor was disappointed in the quality of commodity beef he had handled for another Colorado school district and was pleased at the high quality beef from the meat processor. DPS was impressed by the professionalism and dedication to high quality food shown by the quick-chill processor, including his willingness to devote a chef to develop and test DPS's recipes for Sloppy Joes, beef stew, and chili.

\section{Institutional Changes}

Prior to their involvement in the Learning Lab, SPPS had no specific program for procuring local produce; they did not do advanced menu-planning based on seasonality of produce, they did not use an RFP process, and local produce was featured infrequently on the menu. Institutional changes also took place for the produce vendor. For example, while the vendor stated he could have tracked produce shipments to the farm for food safety reasons, tracking produce by farm origin in order for SPPS to feature it as a locally grown product was new and an extra step he would not have ordinarily made.

For DPS, this VC partnership was a rare circumstance where DPS had a third party prepare finished product to their specifications and where they worked with the quick-chill processor's chefs. However, part of this relationship was viewed as temporary, because in some of the DPS kitchens, staff members are being trained to prepare raw beef. The quick-chill processor made very few institutional changes in order to be able to work with DPS, since he already had a system in place where his chefs worked with another school district to adapt its recipes to large batch proportions. The meat processor regular delivered to Denver, so delivering to the quick-chill processor was not a large change.

\section{Benefits of Participation}

These cases show benefits of VCs for all parties, which can justify the effort needed to participate in them. SPPS was able to get the local produce it wanted, in the proper form and amounts. It also got the story of the farmers, which it used in 
educational and marketing efforts, and which according to SPPS — was well received by students and parents. The produce vendor reported connections with new farmers which increased their ability to source local produce for other clients. The farmers reported getting a fair price, being treated fairly in general, and gaining a market for \#2 grade and surplus produce they otherwise have trouble selling.

DPS was able to get the local product they desired, along with the ability to market local beef in their menus, which they believe has contributed to an increase in students eating school meals. According to conversations between the district partner and kitchen staff, using fresh beef increased the pride of the kitchen workers as they see themselves now "cooking" in the kitchens. For the quick-chill processor, the VC helped to expand his school product line and may open up other school districts to his products.

For the meat processor, the VC provided an additional market for its beef as well as potentially expanding its programs in schools. The meat processor is happy because it has a contract with a large restaurant chain to provide high-end roasts and steaks, which also are sold through the retail store on the processor's premises and directly to restaurants, while DPS gets the ground beef. This relationship now allows the meat processor to confidently process more steers and sell more highend cuts of meat to restaurants since the school districts will buy the ground beef.

\section{Next Steps}

The next step for SPPS is the mainstreaming of local foods by continuing the progress that has been achieved, generating ongoing excitement for local menu items among staff, students, and parents, and by developing new menu ideas for locally available products. For DPS, next steps are a matter of expanding and improving what is currently a pilot program. Key steps include adding local beef items into all the schools' menus and training staff to handle raw meats. Until then, a third-party processor is necessary. From the supply end, the meat processor reported that the business with DPS uses about $10 \%$ of his capacity. The meat processor has asked the district partner for help connecting his operation with other school districts in Colorado that may be interested in similar products.

Future efforts for School Food FOCUS will be to continue creating, testing, refining, and sharing best practices to enable other school districts to benefit from the knowledge gained in the Learning Labs about procurement changes. On-the-ground efforts to get district partners and school districts to collaborate with VC actors in finding common solutions will continue to be of paramount importance.

\section{Lingering Barriers}

Two main barriers remain for SPPS: first, given their northern locale, seasonality will always be a constraint. Second, although working through a distributor solved many of the aggregation and logistical barriers posed by sourcing direct from farmers, maintaining the relationship with farmers - ensuring transparency and fairness as well as communicating the story — requires extra work for someone, be it the distributor, the district partner, or a school district employee.

As DPS develops capacity to handle fresh, local beef, the meat processor will have to grow his school business to other districts so that the price point remains competitive. DPS sources the remainder of its beef needs through pre-cooked USDA commodity beef, although for next year DPS is looking to buy raw commodity beef to be processed by the quick-chill processor. DPS also wishes to market this program even better so that the entire school community knows that local beef is being served to increase participation in school lunch and increase revenue as well.

Keys to Success in the Cases

A key to success in creating the VC was the partnerships among scholars, school food-service professionals, and district partners. SPPS's dedication and vision in setting the goals, their willingness to engage for a sustained period with the Learning Lab project, and their flexibility in taking 
the action steps were critical. Another key to success was SPPS setting its own priorities for change. Finally, at SPPS, systems were put in place to institutionalize the new procedures for gathering information (Abate et al., 2009a), which increases the likelihood of continuing similar processes in the future. The trust SPPS had in the district partner was also critical. The district partner brought a broad perspective on local food issues, particularly the need to address issues of transparency in the process and fair pricing for farmers, which led to these issues being included in the RFP process.

One key to DPS's success was finding a meat supplier willing to work with this system. The meat processor is a strong supporter of small and midscale ranchers and very dedicated to bringing change to the meat industry. His passion for better foods in the community helped to drive this program and was key to other elements aligning. In the absence of the capacity to handle raw meat across all DPS kitchens, the quick-chill processor was an important component to this program moving forward. The quick-chill processor has now become a partner with DPS on other menu items like sauces, beans, and tortillas, which can continue if and when the meat handling service is no longer needed.

In both cases, the district partners played critical roles. In Saint Paul, the district partner brought a breadth of knowledge of agriculture and the distribution chain, and pushed the Learning Lab to consider the need for price transparency and other issues impacting farmers. She also led efforts to vet the RFP. The district partner had been engaged in assisting SPPS before the Learning Lab project began and had greatly increased SPPS's understanding of the farming and supply side issues. In Denver, the district partner played several roles. First, the district partner helped to identify some of the pieces of the VC and made the initial introductions; for example, the district partner knew of the meat processor through his relationship with the American Grassfed Association. The district partner also acted as a "translator" in conversations between the school district and the VC actors. The kind of language that the school food-service professionals use about food procurement and menu planning is a bit different than the kind of language used by commercial operations. Since the district partner was involved in all conversations with all the companies, he served as a translator when discussions got bogged down on differences in terminology, and he helped to keep the conversations going so that the VCs could be formed. The district partner also devoted lots of time to the project, which served DPS well in that they did not have the staff time to devote.

\section{Comparing and Contrasting the Cases}

The two cases have many similarities. Both are relatively large public school districts eager to change their food procurement practices toward more local and sustainable purchases and they are willing to investigate and experiment with new options. Because of their mutual involvement in the Learning Lab, their basic objectives were similar: to serve more locally and sustainably grown healthful foods. Both districts chose to work with vendors who had prior experience in the school food market, who could bring in capacities and skills the school districts lacked: aggregation and processing services from the Minnesota produce vendor, and meat processing and handling in Colorado. Both VCs involved face-to-face meetings among a range of partners to discuss capacities, needs, and constraints, which fostered communication and trust, processes similar to those found in prior VC studies (Stevenson, 2009).

Other similarities reflect the tight budgets school food-service operations face. Both district partners discussed the importance of external resources from School Food FOCUS, which facilitated the efforts to research and experiment with new options. Time devoted by the school districts, district partners, and research teams was crucial for the sustained attention to these efforts. Further up the $\mathrm{VC}$, it was the purchase of surplus products for which producers lacked good markets - ground beef, \#2 and surplus produce - which created price points acceptable for districts while providing secondary income for farmers (with primary income coming from higher quality products like 
steaks and chops and retail-grade produce). Finally, lack of capacity, seasonality of produce, and lower price points continue to limit the quantity of product available to the schools moving forward. However, while each district started with specific priority items, the experience of working through barriers to reach success has encouraged them to continue to think about the possibilities for change and take steps in new directions.

The cases have a few differences as well. Obviously, they have very different geographic and climactic differences: one school is in the cold and rainy Upper Great Lakes area, the other in the warmer and very dry Mountain West. Finally, while the Minnesota case involved an RFP and a contractual process, the Colorado case was built on more informal agreements.

\section{Conclusions}

\section{Roles for Community Partners and Scholars in Values-Based Value Chains}

This paper discusses efforts to bring VC principles to help large school districts improve the quality of their school meals. The paper takes into account the perspectives of community partners who worked with school food-service professionals and scholars to serve more healthful, sustainably and locally grown foods to school meals. Below, we highlight key roles for community partners and scholars in forming partnerships that support sustainable school food procurement.

- Respect the schools' knowledge of their businesses and their desire to serve quality food. School food-service professionals have a deep understanding of their capabilities and constraints and in most cases, a profound desire to serve fresh, healthy food which supports their communities to the maximum extent possible. It is important for all parties to respect and make use of the expertise brought by the other. For the district partner, that includes working to understand the operating environment, constraints, and culture of the participating district.
- Use contacts and knowledge of local food supply chains to investigate, propose, arrange, and monitor. District partners who are well connected and familiar with the local food system can bring many resources to the schools, creating new options and addressing long-standing problems.

- Serve as a liaison between and translator for schools and vendors. A district partner who is familiar with the business practices and language used by both school food service and vendors can facilitate mutually beneficial partnerships and transactions.

- Find strategies to institutionalize efforts with the school district. Written agreements or RFPs may be one way to do this. Others might include new school or district policies, vendor agreements, memoranda of understanding, or the like. As yet, DPS has no formal commitment device with the meat or quick-chill processor, relying on the strength of the relationship among $\mathrm{VC}$ actors to govern the transactions; formal agreements may be needed as the program grows in scale.

- Recognize that outside funding and effort may be needed to bring wholesale changes. Nonprofits and schools both face funding and staffing limits in today's economic climate. However, given current interest around FTS and its ability to generate revenue from increased participation as well as increased public support from the community good will it generates, incremental positive changes are possible. These changes may be accelerated with the infusion of outside funding.

Despite the significant changes in procurement achieved by these school districts, the direct impact on the national scale food system certainly is limited. First, these cases discuss only two food items in two school districts, yet FTS proponents argue that greater financial support is needed if FTS benefits are to be realized at a national level 
(Izumi et al., 2009). Second, others (Allen \& Guthman, 2006) cite the danger of FTS reproducing exploitative economic relationships (such as traditional supply chain practices in which farmers are treated as interchangeable parts rather than strategic partners, as outlined by Pirog (2004)) rather than challenging the underlying systems and institutions (consumer-driven, market-based change) which create the problems FTS purports to address. ${ }^{5}$

While these cases may not tackle systems change at the national level, they contribute to our understanding of how the community development benefits of sustainable school food procurement can be scaled up to work within the context of large districts. By using VC approaches, the benefits can extend to supply chain actors as well. While wholesale transformation of school food requires extensive changes in the globalized food system in which school food is embedded, we believe this study demonstrates the very real possibilities and tangible positive outcomes of partnerships between large schools and VC partners. Smaller schools will benefit to the extent that they purchase from the same vendors as large schools.

The strengths of this study are both the combination of applying the VC model within two large urban public school district settings and the emphasis on the perspectives and roles of and lessons learned by district partners. Findings are limited to one food item in each of two schools and the perspectives of those participating in the project; therefore, generalization of results to another specific setting is inadvisable. Nonetheless, we believe this research can inform partnerships among other school food-service professionals, scholars, and community partners to create VCs that bring broad benefits to school children, local economies, and communities.

\footnotetext{
${ }^{5}$ At the very least, these changes are unlikely to cause direct harm; in the tight budget environment faced by school food service, all changes must be cost neutral. The procurement changes studied here did not result in increased school lunch price or other barriers to participation.
}

Future efforts of School Food FOCUS will be devoted to creating, testing, and sharing processes and mechanisms that can enable schools' procurement changes in the absence of the input of money and resources from the FOCUS project, and in ways that work for districts of many sizes working alone or cooperating with other districts. Efforts to work with districts and to coordinate efforts between schools in order to acquire and manage information, as well as finding and working with supply chain actors to find common solutions, will be paramount to fostering the sustainability of the procurement changes and their concomitant benefits.

\section{References}

Abate, G., Conner, D., Brayley, D., \& Modzelewski, M. (2009a). Learnings from the Lab: Sourcing Local Produce in Saint Paul, Minnesota. School Food FOCUS.

Retrieved from http://www.schoolfoodfocus.org/ site/wp-content/uploads/2010/02/Learningsfrom-the-Lab-Produce-with-RFP.pdf

Abate, G., Conner, D., Brayley, D., \& Modzelewski, M. (2009b). Learnings from the Lab: Improving Milk in Saint Paul, Minnesota. School Food FOCUS.

Retrieved from http://www.schoolfoodfocus.org/ site/wp-content/uploads/2010/02/Learningsfrom-the-Lab-Milk-with-survey-results-andmemo.pdf

Allen, P., \& Guthman, J. (2006). From "old school" to "farm-to-school": Neoliberalization from the ground up. Agriculture and Human V alues, 23(4), 401-415. http://dx.doi.or/10.1007/s10460-0069019-z

Bagdonis, J. M., Hinrichs, C. C., \& Schafft, K. A. (2009). The emergence and framing of farm-to-school initiatives: Civic engagement, health and local agriculture. Agriculture and Human Values, 26, 107119. http://dx.doi.or/10.1007/s10460-008-9173-6

Berkenkamp, J. (2006, January). Making the farm/ school connection. Opportunities and barriers to greater use of locally-grown produce in public schools. Report prepared for the Department of Applied Economics, University of Minnesota. Retrieved from http://www.farmtoschool.org/files/ publications 120.pdf 
Bloom, J. D. \& Hinrichs, C. C. (2011). Moving local food through conventional food system infrastructure: Value chain framework comparisons and insights. Renewable Agriculture and Food Systems, 26, 13-23. http://dx.doi.or/10.1017/ $\underline{\mathrm{S} 1742170510000384}$

Bottemiller, H. (2010). White House, USDA celebrate farm to school program. Food Safety News. Retrieved from http://www.foodsafetynews.com/ 2010/10/white-house-usda-celebrate-dc-farm-toschool-program/

Conner, D. S., Abate, G., Liquori, T., Hamm, M. W., \& Peterson, H. C. (2010). Prospects for more healthful, local and sustainably-produced food in school meals. Journal of Hunger and Environmental Nutrition, 5(4) 416-433. http://dx.doi.or/10.1080/ $\underline{19320248.2010 .527276}$

Conner, D. S., Campbell-Arvai, V., \& Hamm, M. W. (2008). Value in the values: Opportunities for pasture-raised livestock products in Michigan. Renewable Agriculture and Food Systems, 23(1), 62-69. http://dx.doi.or/10.1017/S1742170507002086

Conner, D. S., Cocciarelli, S., Mutch, B., \& Hamm, M. W. (2008). Community-based food systems in Michigan: Cultivating diverse collaborations from the ground up. Journal of Extension, 46(4). Retrieved from http://www.joe.org/joe/2008august/iw1.php

Conner, D. S., Knudson, W. A., Hamm, M. W., \& Peterson, H. C. (2008). The food system as an economic driver: Strategies and applications for Michigan. Journal of Hunger and Environmental Nutrition, 3(4), 371-383. http://dx.doi.or/10.1080/19320240802528849

Feenstra, G. W, Ohmart, J. L., \& Van Soelen, J. (2009). School Food FOCUS year-end evaluation report. Davis, CA.

Goldschmidt, W. (1947). As you sow. New York: Harcourt Brace.

Izumi, B. T., Alaimo, K., \& Hamm, M. W. (2010). Farm-to-school programs: Perspectives of school food service professionals. Journal of Nutrition Education and Behavior, 42(2), 83-91. http://dx.doi.or/10.1016/j.jneb.2008.09.003

Izumi, B. T., Wright, D. W., \& Hamm, M. W. (2009). Farm to school programs: Exploring the role of regionally-based food distributors in alternative agrifood networks. Agriculture and Human Values, 27(3), 335-350. http://dx.doi.or/10.1007/s10460009-9221-x

Izumi, B. T., Wright, D. W., \& Hamm, M. W. (2010). Market diversification and social benefits: Motivations of farmers participating in farm to school programs. Journal of Rural Studies, 26(4), 374-382. http://dx.doi.or/10.1016/j.jrurstud.2010.02.002

Joshi, A., Azuma, A., \& Feenstra, G. W. (2008). Do farm-to-school programs make a difference? Findings and future research needs. Journal of Hunger and Environmental Nutrition, 3(2/3), 229-246. http://dx.doi.or/10.1080/19320240802244025

Kirschenmann, F., Stevenson, S, Buttel, F., Lyson, T., \& Duffy, M. (2008). Why worry about the agriculture of the middle? Retrieved from http://www.agofthemiddle. org/archives/2005/08/why_worry_about.html

Kloppenburg, J., Wubben, D., \& Grunes, M. (2008). Linking the land and the lunchroom: Lessons from the Wisconsin Homegrown Lunch Project. Journal of Hunger and Environmental Nutrition, 3(4), 440-455. http://dx.doi.or/10.1080/19320240802529300

Lawless, G., Stevenson, G. W, Hendrickson, J., \& Cropp, R. (1999). The Farmer-Food Buyer Dialogue Project. University of Wisconsin Center for Cooperatives. Retrieved from http://www.uwcc. wisc.edu/info/ffbuyer/text.html

Lyson, T., Torres, R., \& Welsh, R. (2001). Scale of agriculturalproduction, civic engagement and community welfare. Social Forces, 80(1), 311-327. http://dx.doi.or/10.1353/sof.2001.0079

Minkler, M. (2000). Using participatory action research to build healthy communities. Public Health Reports, 115((2-3), 191-197.

One Tray Coalition. (2009). What can USD $A$ do? Retrieved from http://www.farmtoschool. org/files/publications_243.pdf

Pavlovich, W. D. (2004). Community-based participatory research and Baltimore Healthy Stores: Goals, progress and future steps. Baltimore, MD: Baltimore Healthy Stores, Center for Human Nutrition Johns Hopkins Bloomberg School of Public Health. Retrieved from http://www.healthystores.org/images/ cbpr.pdf 
Pirog, R. (2004). Sharing risks and rewards across partners in pastured livestock, value chains. Kellogg Biological Station, Hickory Corners MI. Retrieved from http://mottgroup.msu.edu/uploads/files/59/ AITFS-Pirog.pdf

Stevenson, G. W., \& Pirog, R. (2008). Values-based supply chains: Strategies for agrifood enterprises of the middle. In T. Lyson, G. W. Stevenson, \& R. Welsh (Eds.), Food and the mid-level farm: Renewing an agriculture of the middle (pp. 119-143). Cambridge, MA: MIT Press.

Stevenson, S. (2009). V alues-based food supply chains: Executive summary. Madison WI. Retrieved from http://www.agofthemiddle.org/archives/2009/11/ value_chain_cas.html

Strohbehn, C. A., \& Gregoire, M. (2008, May). Local food connections. Foodservice considerations (Extension bulletin PM 1853c). Iowa State University Extension. Retrieved from http://www.extension. iastate.edu/publications/pm1853c.pdf

USDA. (2010). Know Your Farmer, Know Your Food: Our mission. Retrieved from http://www.usda.gov/ wps/portal/usda/knowyourfarmer?navtype= $\underline{\text { KYF\&navid=KYF MISSION }}$

USDA Food and Nutrition Service. (2009). National School Lunch Program fact sheet. Retrieved from http://www.fns.usda.gov/cnd/Lunch/About Lunch/NSLPFactSheet.pdf
Vallianatos, M., Gottlieb, R., \& Hasse, M. A. (2004). Farm-to-school: Strategies for urban health, combating sprawl and establishing a community food system approach. Journal of Planning Education, 23(4), 414-423. http://dx.doi.or/10.1177/ 0739456X04264765

Vogt, R. A., \& Kaiser, L. L. (2008). Still a time to act: A review of institutional marketing of regionallygrown food. Agriculture and Human V alues 25, 241255. http://dx.doi.or/10.1007/s10460-007-9106-9

Welsh, R., \& Lyson, T. A. (1997). Farm structure, market structure and agricultural sustainability goals: The case of New York State dairying. American Journal of Alternative Agriculture, 12(1), 14-18. http://dx.doi.org/10.1017/ $\underline{\mathrm{S} 0889189300007128}$

Wright, W., Score, M., \& Conner, D. (2008). Food system makers: Motivational frames for renewing food and agriculture through multi-stakeholder collaboration. Journal of the Community Development Society, 38(3), 39-59. http://dx.doi.or/10.1080/ 15575330709489828 